\title{
Effect of Plasma Pretreatment on Thermal Durability of Thermal Barrier Coatings in Cyclic Thermal Exposure
}

\author{
Sang-Won Myoung, ${ }^{1}$ Zhe Lu, ${ }^{1}$ Yeon-Gil Jung, ${ }^{1}$ Byung-Koog Jang, ${ }^{2}$ Young-Soo Yoo, ${ }^{3}$ \\ Seong-Moon Seo, ${ }^{3}$ Baig-Gyu Choi, ${ }^{3}$ and Chang-Yong Jo ${ }^{3}$ \\ ${ }^{1}$ School of Materials Science and Engineering, Changwon National University, No. 20 Changwondaehakro, \\ Changwon, Gyeongnam 641-773, Republic of Korea \\ ${ }^{2}$ High Temperature Materials Unit, National Institute for Materials Science, 1-2-1 Sengen, Tsukuba, Ibaraki 305-0047, Japan \\ ${ }^{3}$ High Temperature Materials Research Group, Korea Institute of Materials Science, 797 Changwondaero, Changwon, \\ Gyeongnam 641-831, Republic of Korea
}

Correspondence should be addressed to Yeon-Gil Jung; jungyg@changwon.ac.kr

Received 5 March 2014; Accepted 17 April 2014; Published 22 May 2014

Academic Editor: George Z. Kyzas

Copyright (C) 2014 Sang-Won Myoung et al. This is an open access article distributed under the Creative Commons Attribution License, which permits unrestricted use, distribution, and reproduction in any medium, provided the original work is properly cited.

\begin{abstract}
Plasma pretreatment on the top and bond coats was performed and its influence on the thermal durability of thermal barrier coating (TBC) system was investigated through cyclic thermal exposure. Two types of bond coat were prepared by different methods, namely, air plasma spray (APS) and high-velocity oxy-fuel (HVOF), and two kinds of feedstock powder were employed for preparing the top coat in APS process. The better thermal durability was achieved in the vertically cracked TBC with the surface modified bond coat or with the bond coat prepared by APS process. The hardness and fracture toughness values of TBCs increased because of densification of the top coat during cyclic thermal exposure, and the bond coat prepared by HVOF process showed higher values than that by APS process. The TBCs with the surface modified bond coat were more efficient in improving adhesive strength than those without plasma pretreatment on the bond coat. The relationship between microstructure evolution and thermomechanical characteristics of TBCs with plasma pretreatment was discussed in cyclic thermal exposure.
\end{abstract}

\section{Introduction}

Currently, plasma sprayed coatings, especially zirconia-based coatings, are widely used in various industries because of their attractive properties, namely, low thermal conductivity, high coefficient of thermal expansions (CTEs), and oxidation resistance [1]. In particular, thermal barrier coatings (TBCs) are used to protect and insulate metallic substrates in hotsection components, such as blades, vanes, and combustor parts in gas turbines [2,3]. Generally, the TBC system consists of a substrate of nickel based superalloy, an intermetallic bond coat of MCrAlY ( $M=$ nickel and/or cobalt), and a ceramic top coat. The bond coat plays an important role in preventing the substrate from oxidation and in decreasing thermal expansion mismatch between the top coat and the substrate, and the top coat is prepared either by air-plasma spray (APS) process or by electron beam-physical vapor deposition process using 7-8 wt\% yttria $\left(\mathrm{Y}_{2} \mathrm{O}_{3}\right)$-stabilized zirconia $\left(\mathrm{ZrO}_{2}\right)$, which provides a thermal barrier function to TBC system [4]. Also, the TBC system can provide a major reduction in the surface temperature of metallic components when combined with the use of internal air cooling on the underlying metallic components, indicating that an increase in thickness of the top coat reduces the surface temperature of the cooled components in gas turbine engines at the rate 4$9^{\circ} \mathrm{C}$ per $25 \mu \mathrm{m}$ [5]. The microstructure, such as oxide scales and porosity, depends on the composition of feedstock powder, manufacturing process, coating parameter, and working condition $[3,6]$. The thermal durability of TBCs is closely related to its microstructure, and the lifetime performance of TBCs decreases sharply as the applied temperature increases. Therefore, an improvement in thermal stability through 
microstructure development in the top coat of TBCs has been the main subject of several studies on the protective coating system [7-9].

In the present study, the bond and top coats have been modified using different feedstock powders and coating systems. The newly developed TBCs through the microstructure design using the APS and HVOF systems could be promising for use in TBC application. To adjust TBCs to a real application for hot-section components in gas turbines, two types of bond coat were prepared using the APS and HVOF processes, and then the plasma pretreatment was performed on the surfaces of each bond coat to improve adhesion between the bond and top coats by removing pollutants and by controlling surface roughness. The vertically cracked top coats with the dense and porous microstructures were prepared using the TriplexPro-200 system. In order to understand the effects of plasma pretreatment on the thermal durability and mechanical properties of TBCs, the microstructure evolution in the bond and top coats was investigated through cyclic thermal exposure and the mechanical properties with feedstock powder were estimated, including the thermal stability at the interface of the bond and top coats. The cyclic thermal exposure tests were performed at $1100^{\circ} \mathrm{C}$ to observe the thermal durability of the vertically cracked top coats with different bond coat species as a function of plasma pretreatment. Advantages of plasma pretreatment on the bond and top coats for enhancing the thermal durability of TBCs in cyclic thermal exposure were discussed, based on microstructure evolution and mechanical properties.

\section{Experimental Procedure}

2.1. Preparation of TBCs. A nickel-based superalloy with 25.4 and $5 \mathrm{~mm}$ in diameter and thickness, respectively, was used as a substrate. The substrate was sand blasted using an alumina $\left(\mathrm{Al}_{2} \mathrm{O}_{3}\right)$ powder with particle size of 50 mesh, and then the APS and HVOF processes were conducted within $2 \mathrm{~h}$. Two kinds of feedstock powder were used and two types of coating process were employed to coat a bond coat on the substrate: AMDRY 962 (Sulzer Metco Holding AG, Switzerland, nominal composition of $\mathrm{Ni}-22 \mathrm{Cr}-10 \mathrm{Al}-1.0 \mathrm{Y}$ in $\mathrm{wt} \%$ and particle size of 56-106 $\mu \mathrm{m}$ ) for APS process using TriplexPro200 system (Plasma Technik, Sulzer Metco, Westbury, NY, USA) and AMDRY 997 (Sulzer Metco Holding AG, nominal composition of $\mathrm{Ni}-23 \mathrm{Co}-20 \mathrm{Cr}-8.5 \mathrm{Al}-4 \mathrm{Ta}-0.6 \mathrm{Y}$ in $\mathrm{wt} \%$ and particle size of approximately $37 \mu \mathrm{m}$ ) for HVOF process using Diamond Jet-2600 DJM (Plasma Technik). The thickness of the bond coat was approximately $d=200 \pm 20 \mu \mathrm{m}$. Two kinds of feedstock powder were used as a top coat, which were deposited onto the bond coat: METCO 204 C-NS (hereinafter C-NS; Sulzer Metco Holding AG, Switzerland, 8 wt $\% \mathrm{Y}_{2} \mathrm{O}_{3}$ doped in $\mathrm{ZrO}_{2}$, particle size of 45-125 $\mu \mathrm{m}$ ) and METCO 204 NS (hereinafter NS; Sulzer Metco Holding AG, 8 wt $\% \mathrm{Y}_{2} \mathrm{O}_{3}$ doped in $\mathrm{ZrO}_{2}$, particle size of 11-125 $\mu \mathrm{m}$ ) [10]. The thickness of the top coat was approximately $d=1,200 \pm 200 \mu \mathrm{m}$. The plasma pretreatment on the surfaces of both the bond and top coats was performed by a plasma flame using TriplexPro200 equipment without powder feeding. The conditions of plasma pretreatment were five passes with the regulating gun's moving speed of $250 \mathrm{~mm} / \mathrm{s}$ and with the distances of 150 and $50 \mathrm{~mm}$ for the bond and top coats, respectively. The detailed spray parameters for the APS and HVOF processes are indicated in Table 1 . These parameters were selected from conditions indicated by the manufacturer of the powders trying to guarantee the best deposition characteristics.

2.2. Characterization. The TBC specimens with and without the plasma pretreatment were preprocessed to observe crosssectional microstructure and to measure mechanical properties. The cross-sectional microstructure of TBC specimens was observed using a scanning electron microscope (SEM, JEOL JSM-5610, Japan). The cyclic thermal exposure tests were performed until 381 cycles in a specially designed furnace at $1100^{\circ} \mathrm{C}$-the upper surface of the specimen was exposed to high temperature and the bottom surface was cooled with a natural air, showing the temperature difference of $150^{\circ} \mathrm{C}$ between the upper and bottom surfaces. The holding and cooling times were 60 and $20 \mathrm{~min}$, respectively. The failure criterion was defined as $25 \%$ buckling or spallation of the top coat in the tests. The hardness and fracture toughness values before and after the tests were measured using a microindenter (HM-114, Mitutoyo Corp., Japan) for loads of 3 and $30 \mathrm{~N}$ with a Vickers tip, respectively [11]. Nanoindentation was carried out on the sectional planes of each TBC to determine elastic modulus using a nanoindenter (Nanoinstruments, MTS Systems Corp., Eden Prairie, USA) employing a Berkovich tip (radius $<100 \mathrm{~nm}$ ). TBC specimens employed in this study are summarized in Table 2 . The adhesive strength was measured with the as-prepared TBC specimens bonded to the jig fixture by an epoxy adhesive in the oven for $3 \mathrm{~h}$ at $200^{\circ} \mathrm{C}$, according to the ASTM standard (ASTM-C-633-01) [12].

\section{Results and Discussion}

3.1. As-Prepared Microstructure. The cross-sectional microstructures of TBC specimens at a low magnification, which were prepared with different feedstock powders and coating processes, are shown in Figure 1. The microstructure of the vertically cracked top coats prepared with C-NS (Figures 1(a) to 1(c)) was relatively porous, compared to that with NS (Figures $1(\mathrm{~d})$ to $1(\mathrm{f})$ ). The C-NS feedstock powder has a disadvantage for powder melting in the plasma flame owing to the bigger particle size rather than the NS feedstock powder, showing the porosities of the top coats prepared with C-NS and NS in the ranges of $15 \pm 3$ and $10 \pm 2 \%$, respectively. The vertical type cracks were developed by a thermal shock after the plasma treatment on the surface of the top coat by the plasma flame. The vertical cracks in the top coats of C-NS and NS were generated in the ranges of 1620 and $20-24$ per $10 \mathrm{~mm}$, respectively, showing the relatively large number of vertical cracks in the top coat with NS. The top coat with NS was denser than that with C-NS, which is a major cause leading to a large number of vertical cracks in the top coat with NS. The surface of the top coat with C-NS showed a remelted layer because of the relatively low purity of C-NS [13]. The top coats with C-NS and NS were 


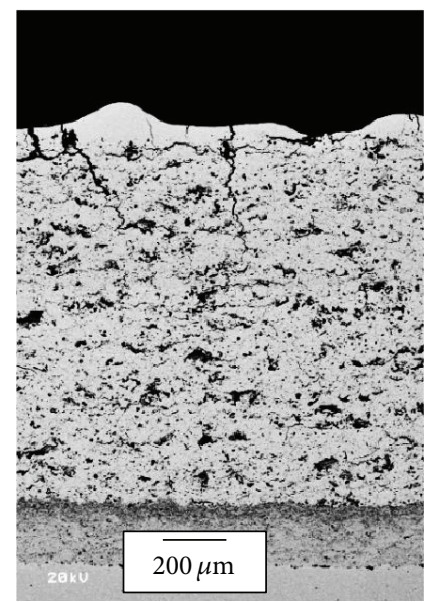

(a)

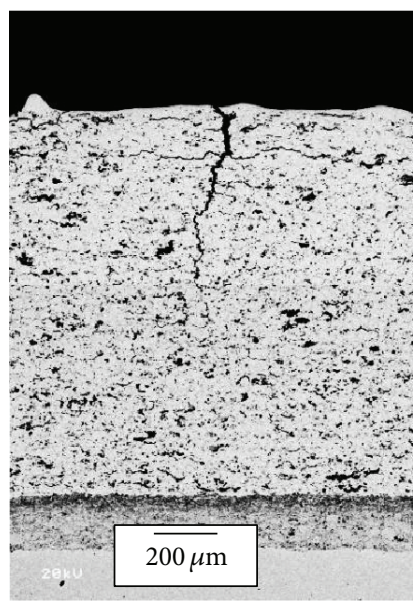

(d)

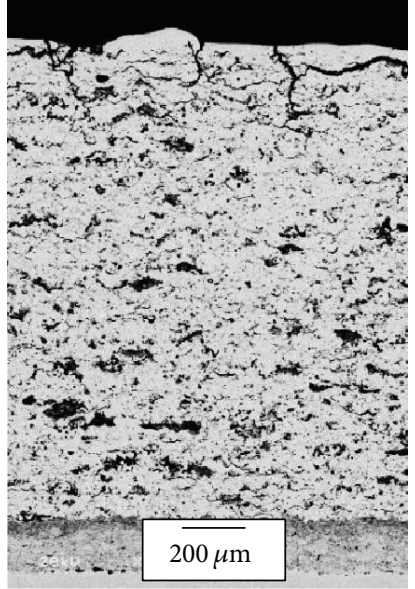

(b)

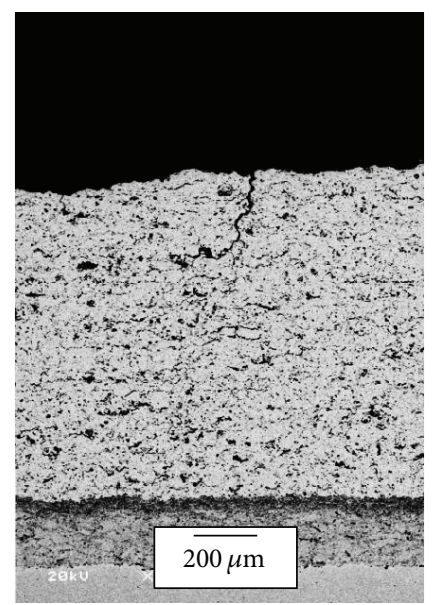

(e)

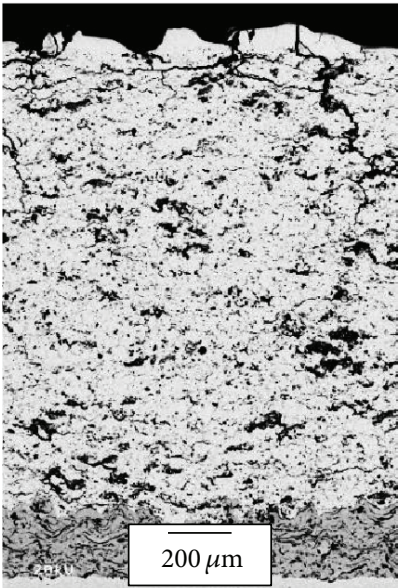

(c)

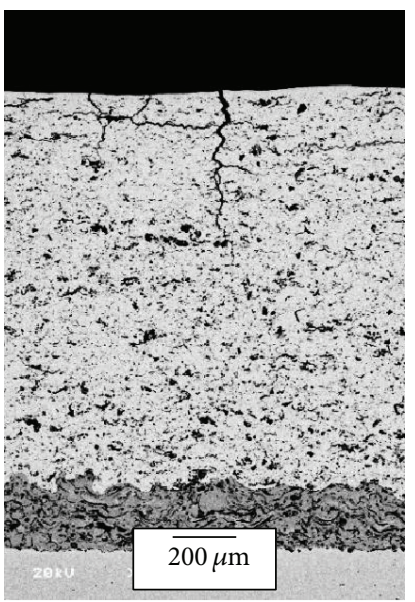

(f)

Figure 1: Cross-sectional microstructures of TBCs with and without plasma pretreatment on bond coat: (a) 204 C-NS with HVOF bond coat without plasma pretreatment (TBC-A), (b) 204 C-NS with HVOF bond coat with plasma pretreatment (TBC-B), (c) 204 C-NS with APS bond coat without plasma pretreatment (TBC-C), (d) 204 NS with HVOF bond coat without plasma pretreatment (TBC-D), (e) 204 NS with HVOF bond coat with plasma pretreatment (TBC-E), and (f) 204 NS with APS bond coat without plasma pretreatment (TBC-F).

TABLE 1: Coating parameters for preparing the bond and top coats.

\begin{tabular}{|c|c|c|c|}
\hline \multirow{2}{*}{ Parameters } & \multicolumn{2}{|c|}{ Bond coat } & \multirow{2}{*}{ Top coat (APS) } \\
\hline & APS & HVOF & \\
\hline Feedstock species & AMDRY 962 & AMDRY 997 & $\mathrm{C}-\mathrm{NS} / \mathrm{NS}$ \\
\hline Feed rate $(\mathrm{g} / \mathrm{min})$ & 90 & 40 & 100 \\
\hline Gun to working distance (mm) & 180 & 250 & 150 \\
\hline Gun moving speed (mm/s) & 500 & 700 & 500 \\
\hline Current (A) & 450 & - & 540 \\
\hline Voltage $(\mathrm{V})$ & 90 & - & 99 \\
\hline Primary and secondary gas $(\ell / \mathrm{min})(\mathrm{Ar} / \mathrm{He})-\mathrm{APS},\left(\mathrm{Air} / \mathrm{O}_{2} / \mathrm{H}_{2}\right)-\mathrm{HVOF}$ & $30 / 20$ & $184 / 98 / 453$ & $15 / 5$ \\
\hline Step distance $(\mathrm{mm})$ & 8 & 8 & 5 \\
\hline
\end{tabular}

well deposited with $d \gg 1,000 \mu \mathrm{m}$ and showed the typical microstructure developed in the commercial APS process. The amount of oxides in the bond coat by HVOF process was smaller than that by APS process because the Diamond Jet2600 DJM system can produce a higher particle velocity of about $850 \mathrm{~m} / \mathrm{s}$, compared with the TriplexPro-200 system of about $560 \mathrm{~m} / \mathrm{s}$ [14].

The interface microstructures between the bond and top coats of the TBCs designed in this study are shown in Figure 2. The TBCs prepared with four conditions showed 


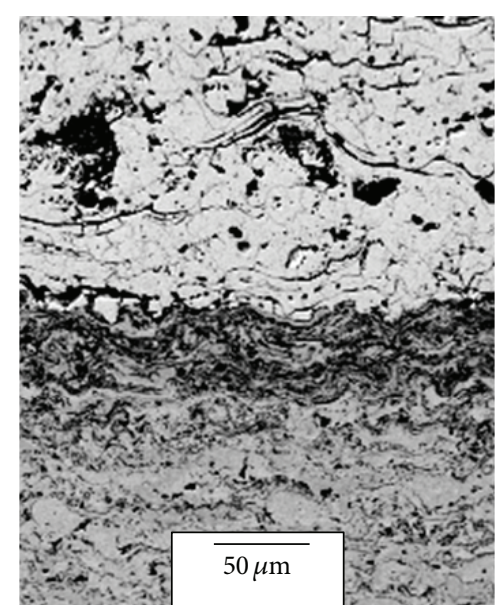

(a)

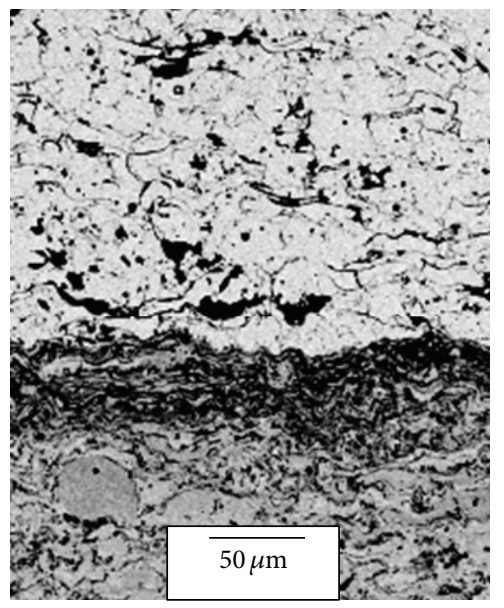

(d)

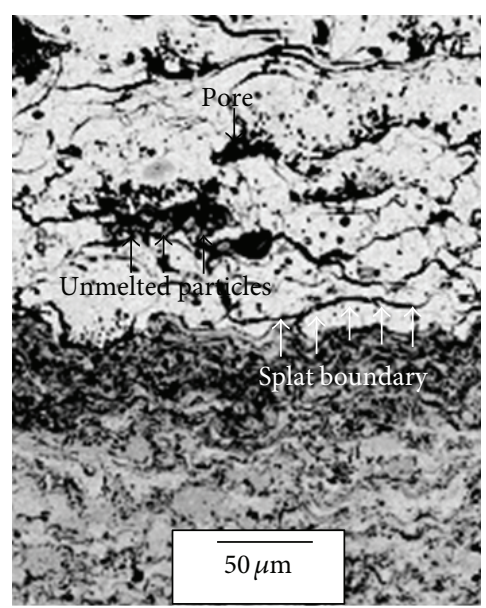

(b)

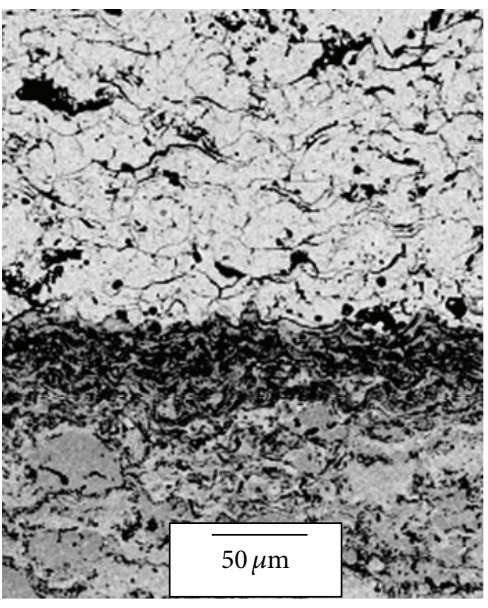

(e)

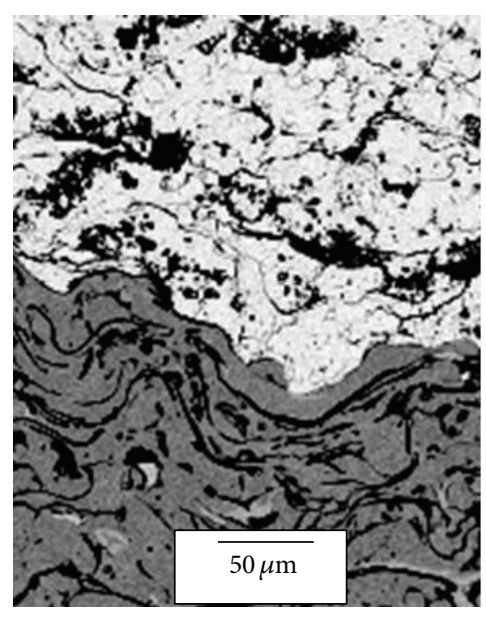

(c)

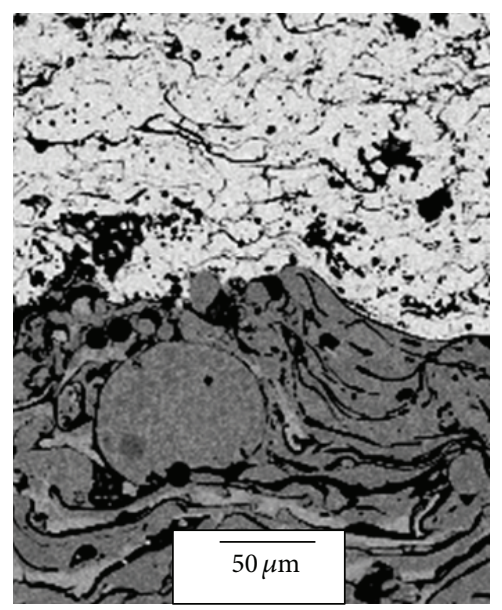

(f)

Figure 2: Highly magnified microstructures at the interfaces of the top and bond coats in TBCs: (a) TBC-A, (b) TBC-B, (c) TBC-C, (d) TBC-D, (e) TBC-E, and (f) TBC-F.

TABLE 2: TBC specimens used in this study for evaluating thermal durability.

\begin{tabular}{lccc}
\hline Specimen & Bond coat & Top coat & Plasma treatment (top coat/bond coat) \\
\hline TBC-A & AMDRY 997 (HVOF) & 204 C-NS (APS) & Done/None \\
TBC-B & AMDRY 997 (HVOF) & 204 C-NS (APS) & Done/Done \\
TBC-C & AMDRY 962 (APS) & 204 C-NS (APS) & Done/None \\
TBC-D & AMDRY 997 (HVOF) & 204 NS (APS) & Done/None \\
TBC-E & AMDRY 997 (HVOF) & 204 NS (APS) & Done/Done \\
TBC-F & AMDRY 962 (APS) & 204 NS (APS) & Done/None \\
\hline
\end{tabular}

a sound condition without any cracking or delamination at the interface. The intrinsic defects, such as global pores, splat boundaries, and oxide materials, were uniformly dispersed in all of the as-prepared top coats. The relatively dense top coat with NS (Figures 2(d) to 2(f)) contained the narrower and relatively uniform "splat" boundaries/cracks, whereas the relatively porous top coat with C-NS (Figures 2(a) to 2(c)) indicated the thicker "splat" boundaries/cracks, large pores, and un-melted particles.
3.2. Cyclic Thermal Exposure. The cross-sectional microstructures at the interfaces of the TBCs which survived after cyclic thermal exposure for 381 cycles (8,000 EOH: equivalent operating hour) are shown in Figure 3. The EOH concept is usually used for estimating the lifetime of gas turbines in the field [3]. The maintenance and inspection interval units are performed based on the EOH rather than the actual running hours. In this study, EOH was estimated as an approximate value, multiplying the number of cycles by 21 . In the cyclic 


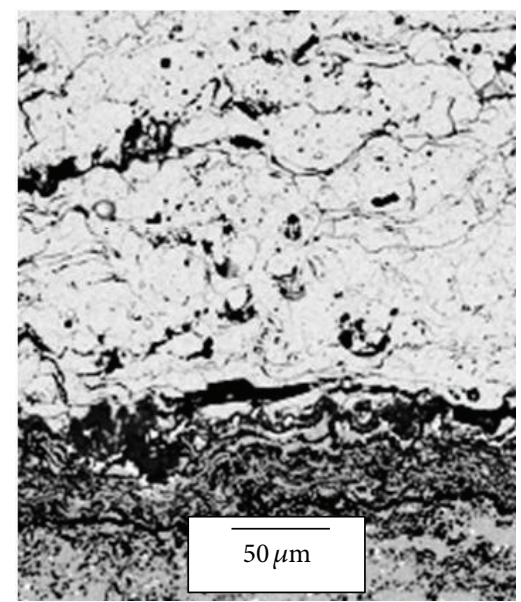

(a)

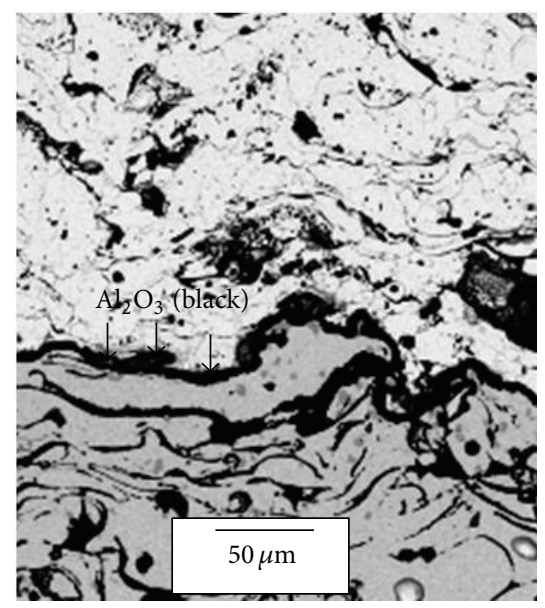

(c)

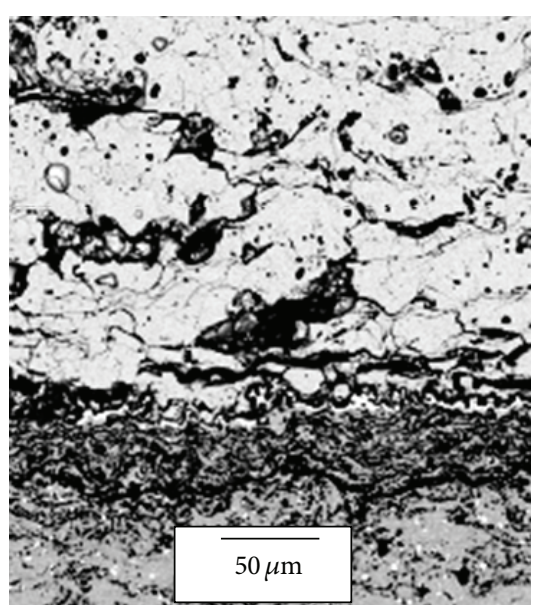

(b)

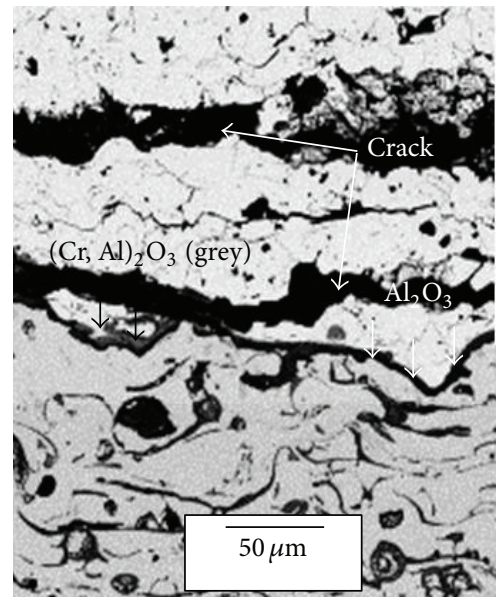

(d)

Figure 3: Highly magnified microstructures at the interfaces of the top and bond coats in TBCs after cyclic thermal exposure tests for 381 cycles: (a) TBC-A, (b) TBC-B, (c) TBC-C, and (d) TBC-F.

thermal exposure tests, the TBCs with C-NS showed a sound condition at the interface without delamination up to 381 cycles (see Figures 3(a) to 3(c)), even though the small and narrow cracks were generated at the interface. However, the TBCs with NS were delaminated in the ranges of 200-240 and 340-360 cycles without and with the plasma pretreatment on the bond coat prepared with HVOF process, respectively, while the TBC with NS on the APS bond coat without the plasma pretreatment survived after 381 cycles, even though the relatively thick cracks were observed at the interface (Figure 3(d)). Thus, in the case of the top coat with a dense microstructure (e.g., the top coat with NS), the TBC system prepared by APS process implies better thermal stability than that by HVOF process, indicating that the plasma pretreatment can improve the thermal durability. Usually, a dense microstructure in top coat promotes heat transfer and thermal diffusion, and shows less strain tolerance than a porous one. The surviving specimens (Figure 3) showed an oxidation phenomenon at the interface between top and bond coats and inside of the bond coat. The effects of the surface modified bond coat and the coating process on the thermal stability were verified in Figure 3 . The small horizontal cracks were integrated into the long and thick ones in the TBC with NS, whereas the microstructure of the top coat in the TBC with C-NS was densified after cyclic thermal exposure.

After thermal exposure for 381 cycles, the TGO layers of both the C-NS and NS TBC systems in the surviving specimens were developed below $10 \mu \mathrm{m}$. If the thickness of TGO layer is greater than $10 \mu \mathrm{m}$, the interface between TGO layer and top coat normally starts to be delaminated and a failure phenomenon is shown [15]. With increasing the surface temperature of top coat, the thermal expansion mismatch plays a more dominant role in failure or delamination of TBC, and the oxidation of bond coat leads to a change in sign of stresses due to the smaller CTEs of TGO layer. The formation and growth of the TGO result in the depletion of $\mathrm{Al}$ in bond coat. Usually, the duplex oxide scale was formed in TGO layer: black color is formed early and gray one is formed late. The duplex oxide scale is composed of the inner (black color; $\mathrm{Al}_{2} \mathrm{O}_{3}$ ) and outer (gray color; $\mathrm{Cr}_{2} \mathrm{O}_{3}, \mathrm{NiAl}_{2} \mathrm{O}_{4}$, and other 


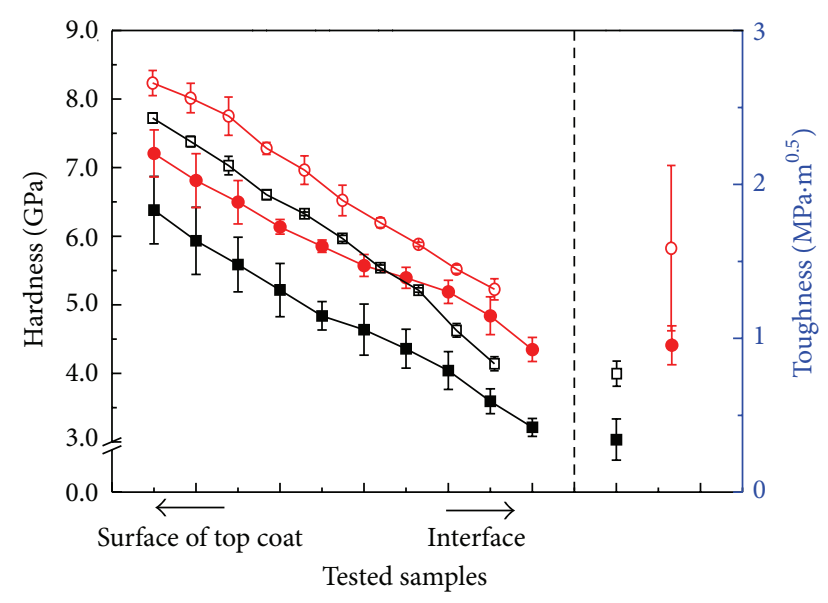

METCO 204 NS

- - As-prepared

-O- After 381 cycles (8.000 EOH)

METCO 204 C-NS

- As-prepared

$\square-$ After 381 cycles $(8.000 \mathrm{EOH})$

FIGURE 4: Hardness and fracture toughness values of TBCs before and after cyclic thermal exposure tests for 381 cycles. Indentation was conducted on the sectional surface with 3 and $30 \mathrm{~N}$ for hardness and fracture toughness, respectively.

spinel structures) layers [16]. In EDS analysis of the TGO layer, the greater part of the TGO area was $\alpha-\mathrm{Al}_{2} \mathrm{O}_{3}$, and some of them were $\left(\mathrm{Cr}, \mathrm{Al}_{2} \mathrm{O}_{3}\right.$ layer. In our study, the TBCs after the plasma pretreatment showed better thermal durability than those without the plasma pretreatment, when the same condition was employed to prepare the bond coat, especially in the HVOF bond coat. The failure mechanisms of plasma sprayed TBCs involve a complex function of defects present within the top coat and at the interface region and are related to how these defects respond to cyclic thermal exposure. The observation and failure mechanisms could be well explained with previous works $[6,17,18]$. According to Padture et al., during thermal cycling, progressive roughening of the bond coat/TGO/top coat interfaces occurs due to cyclic creep of the bond coat [17]. According to Rabiei and Evans [6] and Ranjbar-Far et al. [18], the preference for crack growth in TBC is consistent with the low transverse fracture toughness of TBC by APS process.

3.3. Mechanical Properties. The hardness and fracture toughness values of the top coats designed in this study were measured using a Vickers indentation method. Results before and after the cyclic thermal exposure tests are shown in Figure 4. In the case of as-prepared TBCs, the hardness values of the TBCs with C-NS and NS were determined to be $6.4 \pm 0.1$ to $3.2 \pm 0.1$ and $7.2 \pm 0.3$ to $4.3 \pm 0.2 \mathrm{GPa}$, respectively. The hardness values were decreased linearly as the indentation position was moved to the interface between the bond and top coats. The hardness values obtained in the top coats with the plasma pretreatment were higher than those of the top coats previously reported with nominal values of 3.2 and $4.4 \mathrm{GPa}$ for TBCs with C-NS and NS powders, respectively [2, 3]. After cyclic thermal exposure, the hardness values of the vertically cracked TBCs with C-NS and NS were determined to be $7.8 \pm 0.1$ to $4.2 \pm 0.1$ and $8.3 \pm 0.2$ to $5.3 \pm 0.2 \mathrm{GPa}$, respectively. The hardness values were increased in both cases after cyclic thermal exposure for 381 cycles. The increase in the hardness value is due to the densification of the top coat during cyclic thermal exposure. The hardness values were much similar with our previous studies $[3,19]$. It was verified that the hardness value is in a good agreement with the microstructure evolution. The fracture toughness values of the TBCs with C-NS and NS were determined to be $0.3 \pm 0.1$ and $0.9 \pm 0.1 \mathrm{MPa} \cdot \mathrm{m}^{1 / 2}$, respectively. The fracture toughness value obtained in the TBC with NS was higher than that of the top coat previously reported as a nominal value of $0.25 \mathrm{MPa} \cdot \mathrm{m}^{0.5}[3,5]$. After cyclic thermal exposure for 381 cycles, the fracture toughness values of the TBCs with C-NS and NS were increased to $0.7 \pm 0.1$ and $1.6 \pm 0.5 \mathrm{MPa} \times \mathrm{m}^{0.5}$, respectively, showing a large standard deviation in the TBC with NS.

The effects of microstructure and cyclic thermal exposure on elastic modulus are shown in Figure 5. In the case of asprepared TBCs, the modulus values of the top coats in the TBCs with C-NS and NS were determined to be $105 \pm 7$ and $108 \pm 9 \mathrm{GPa}$, respectively. APS process showed lower value than $\mathrm{HVOF}$ process in the bond coat, which were determined to be $115 \pm 7$ and $138 \pm 16 \mathrm{GPa}$ for the APS and HVOF processes, respectively. The modulus values were obtained in the middle of specimen. Therefore, there was not any effect of the plasma pretreatment. The modulus values measured in this study for the TBCs with C-NS and NS were slightly higher than the previously reported values with nominal values of $90 \mathrm{GPa}$, showing similar values to the bond coat. After cyclic thermal exposure, the modulus values of the top coats in the TBCs with C-NS and NS were slightly increased, owing to densification of the top coats, which were determined to be $109 \pm 5$ and $113 \pm 12 \mathrm{GPa}$, respectively. However, the modulus values in the bond coat were greatly increased because of oxidation, being $176 \pm 5$ and $161 \pm$ $3 \mathrm{GPa}$ for the HVOF bond coats with and without the plasma pretreatment, respectively, and $176 \pm 2$ and $145 \pm 12 \mathrm{GPa}$ for the APS bond coats with C-NS and NS, respectively. The modulus variation in the bond coats was similar to those of hardness and toughness. The elastic modulus values before and after cyclic thermal exposure and with and without the plasma pretreatment were in a good agreement with the microstructure evolution.

3.4. Adhesive Strength. The adhesive strength in TBC system is strongly dependent on its microstructure, and the fracture origin is related to the interface microstructure of the bond and top coats. The adhesive strength values of each TBC employed in this study are shown in Figure 6. The adhesive strength values of the TBCs with C-NS on the HVOF bond coats without and with the plasma pretreatment were determined to be $5.4 \pm 0.5$ and $6.4 \pm 0.1 \mathrm{MPa}$, respectively, and that on the APS bond coat without the plasma pretreatment was determined to be $3.1 \pm 0.2 \mathrm{MPa}$. The TBC with NS on 


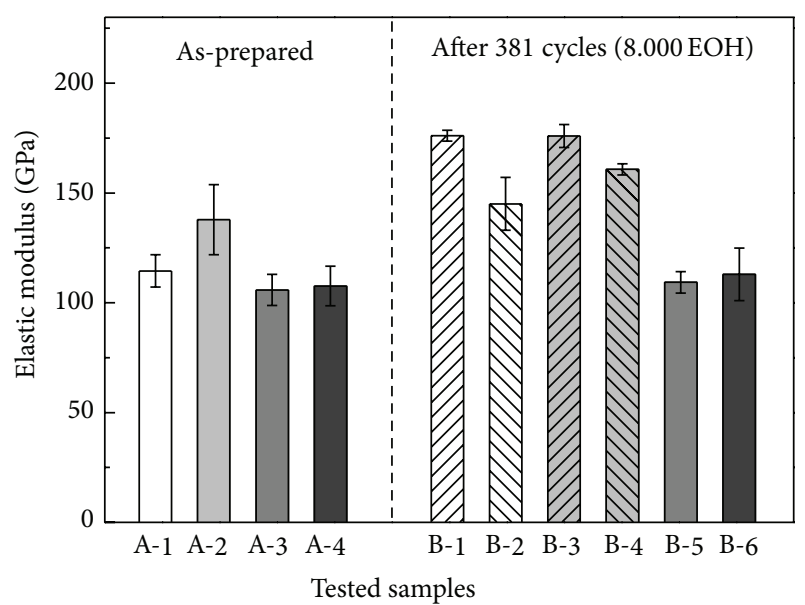

FIGURE 5: Elastic modulus values of TBCs before and after cyclic thermal exposure tests for 381 cycles: (A-1) APS bond coat, (A2) HVOF bond coat, (A-3) C-NS top coat, (A-4) NS top coat, (B1) and (B-2) APS bond coat with the C-NS and NS top coats, respectively, (B-3) and (B-4) HVOF bond coat with and without plasma pretreatment, respectively, (B-5) C-NS top coat, and (B-6) NS top coat. A and B series indicate the elastic modulus before and after cyclic thermal exposure tests for 381 cycles, respectively.

the HVOF bond coat with the plasma pretreatment showed the highest strength value of $6.5 \pm 0.1 \mathrm{MPa}$, because of the relatively dense microstructure and the modified interface with the plasma pretreatment, while those of the TBCs with NS on the HVOF and APS bond coats without the plasma pretreatment being $5.8 \pm 0.4$ and $4.7 \pm 0.1 \mathrm{MPa}$, respectively. The TBCs prepared with the HVOF bond coats showed higher adhesive strength values than those with the APS bond coat, independent of the plasma pretreatment, because $\mathrm{HVOF}$ process gives a lower interface stresses and a better strain isolation in TBC system.

The TBC system with the surface modified HVOF bond coat provided better adhesive strength than those with the APS bond coat without the plasma pretreatment, because of the relatively dense interface microstructure and the structural efficiency with the plasma pretreatment. The adhesive strength values measured in the study were a little lower than those of TBCs previous reported, which were prepared with APS process [2]. However, the thickness in the previous study was less than $1,000 \mu \mathrm{m}$ and there were no vertical type cracks in the top coat. Usually, the adhesive strength is dependent on the coating thickness and decreased with increasing the thickness because of the thermal shock and dimension change during coating process. Delamination in the adhesive strength tests was created within the top coat, not at the interface, which would be originated from the vertical type cracks. Therefore, it can be said that the interface stability was improved by the plasma pretreatment.

\section{Conclusions}

The microstructures of TBCs were well controlled with different feedstock powders in the bond and top coats. The

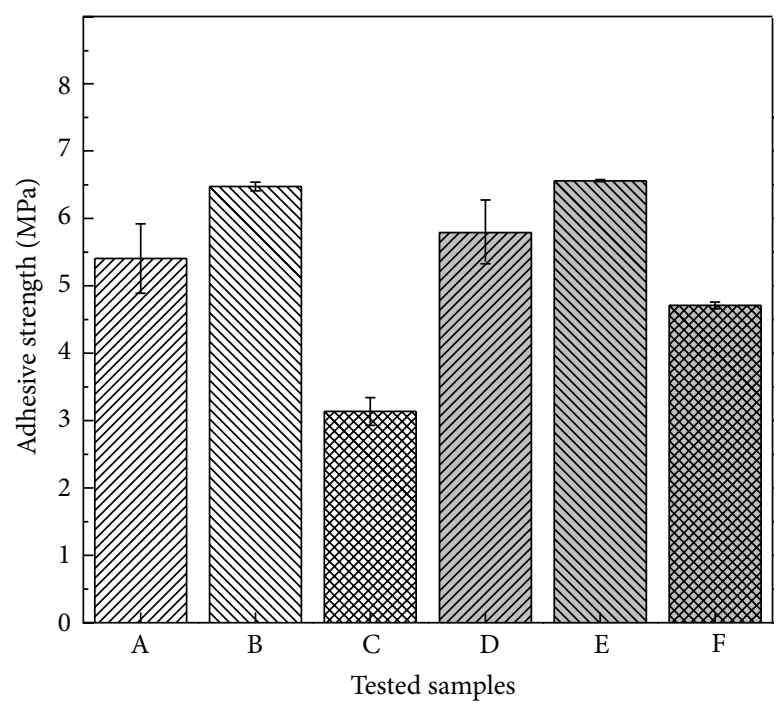

(A) $204 \mathrm{C}-\mathrm{NS}$ with HVOF bond coat without plasma pretreatment

(B) $204 \mathrm{C}-\mathrm{NS}$ with HVOF bond coat with plasma pretreatment

(C) $204 \mathrm{C}-\mathrm{NS}$ with APS bond coat without plasma pretreatment

(D) $204 \mathrm{NS}$ with HVOF bond coat without plasma pretreatment

(E) $204 \mathrm{NS}$ with HVOF bond coat with plasma pretreatment

(F) 204 NS with APS bond coat without plasma pretreatment

FIgURE 6: Adhesive strength values of as-prepared TBCs: (A) TBCA, (B) TBC-B, (C) TBC-C, (D) TBC-D, (E) TBC-E, and (F) TBC-F.

TBCs with C-NS, having a relatively porous microstructure, showed a sound condition without delamination at the interface between the bond and top coats after cyclic thermal exposure for 381 cycles, independent of bond coat species. Delamination at the interface between the bond and top coats readily occurred in the TBCs with a relatively dense microstructure. The TGO layer was not fully developed in the surviving specimens tested. In the TBCs with the HVOF bond coat, the plasma pretreatment on the bond coat enhanced the thermal durability. The hardness and fracture toughness values in all TBC specimens tended to increase with cyclic thermal exposure because of the densification phenomenon, depending on the as-prepared microstructure. However, the elastic modulus was not affected by feedstock species and cyclic thermal exposure in the top coat, whereas the elastic modulus values were increased after cyclic thermal exposure in the bond coats, resulting from oxidation. The adhesive strength values were determined to be about 6.5 and $6.4 \mathrm{MPa}$ for the TBC systems with C-NS and NS on the modified HVOF bond coat, respectively, indicating that the plasma pretreatment on the bond coat provided a better adhesion to TBC system. This evidence allows us to control the interface stability and thermal durability of TBC and to propose an efficient coating in insulating and protecting the substrate from high temperature environments.

\section{Conflict of Interests}

The authors declare that there is no conflict of interests regarding the publication of this paper. 


\section{Acknowledgments}

This work was supported by the National Research Foundation of Korea (NRF) Grant funded by the Korean government (MSIP) (2011-0030058), by the Human Resources Development program (20134030200220) and the Technology Innovation Program (10043795) funded by the Korea government Ministry of Trade, Industry and Energy, and by the Korea Institute of Materials Science (KIMS) in 2013.

\section{References}

[1] F. Cernuschi, S. Ahmaniemi, P. Vuoristo, and T. Mäntylä, "Modelling of thermal conductivity of porous materials: application to thick thermal barrier coatings," Journal of the European Ceramic Society, vol. 24, no. 9, pp. 2657-2667, 2004.

[2] S.-W. Myoung, J.-H. Kim, W.-R. Lee, Y.-G. Jung, K.-S. Lee, and U. Paik, "Microstructure design and mechanical properties of thermal barrier coatings with layered top and bond coats," Surface and Coatings Technology, vol. 205, no. 5, pp. 1229-1235, 2010.

[3] P.-H. Lee, S.-Y. Lee, J.-Y. Kwon et al., “Thermal cycling behavior and interfacial stability in thick thermal barrier coatings," Surface and Coatings Technology, vol. 205, no. 5, pp. 1250-1255, 2010.

[4] C. G. Levi, "Emerging materials and processes for thermal barrier systems," Current Opinion in Solid State and Materials Science, vol. 8, no. 1, pp. 77-91, 2004.

[5] A. D. Jadhav, N. P. Padture, E. H. Jordan, M. Gell, P. Miranzo, and E. R. Fuller Jr., "Low-thermal-conductivity plasma-sprayed thermal barrier coatings with engineered microstructures," Acta Materialia, vol. 54, no. 12, pp. 3343-3349, 2006.

[6] A. Rabiei and A. G. Evans, "Failure mechanisms associated with the thermally grown oxide in plasma-sprayed thermal barrier coatings," Acta Materialia, vol. 48, no. 15, pp. 3963-3976, 2000.

[7] “GE Energy," GER-3569G, Schenectady, NY, USA, http://site.geenergy.com/prod_serv/products/tech_docs/en/downloads/ ger3569g.pdf.

[8] D. Zhu, S. R. Choi, and R. A. Miller, "Development and thermal fatigue testing of ceramic thermal barrier coatings," Surface and Coatings Technology, vol. 188-189, no. 1-3, pp. 146-152, 2004.

[9] Y. H. Sohn, E. Y. Lee, B. A. Nagaraj, R. R. Biederman, and R. D. Sisson Jr., "Microstructural characterization of thermal barrier coatings on high pressure turbine blades," Surface and Coatings Technology, vol. 146-147, pp. 132-139, 2001.

[10] "Sulzer-Metco Thermal Spray Materials Guide," http://www sulzermetco.com.

[11] B. R. Lawn, Fracture of Brittle Solids, Cambridge University Press, Cambridge, UK, 2nd edition, 1993.

[12] “ASTM Standards C633-79," American Society of Testing and Materials, Philadelphia, Pa, USA.

[13] S. Paul, A. Cipitria, I. O. Golosnoy, L. Xie, M. R. Dorfman, and T. W. Clyne, "Effects of impurity content on the sintering characteristics of plasma-sprayed zirconia," Journal of Thermal Spray Technology, vol. 16, no. 5-6, pp. 798-803, 2007.

[14] "Sulzer Metco," http://www.sulzermetco.com/de/Portaldata/13/ Resources/documents/equipment/DSE_TriTriplex-200_EN5 web.pdf.

[15] K. Ma and J. M. Schoenung, "Isothermal oxidation behavior of cryomilled NiCrAlY bond coat: homogeneity and growth rate of TGO," Surface and Coatings Technology, vol. 205, no. 21-22, pp. 5178-5185, 2011.

[16] W. R. Chen, X. Wu, B. R. Marple, R. S. Lima, and P. C. Patnaik, "Pre-oxidation and TGO growth behaviour of an airplasma-sprayed thermal barrier coating," Surface and Coatings Technology, vol. 202, no. 16, pp. 3787-3796, 2008.

[17] N. P. Padture, M. Gell, and E. H. Jordan, "Thermal barrier coatings for gas-turbine engine applications," Science, vol. 296, no. 5566, pp. 280-284, 2002.

[18] M. Ranjbar-Far, J. Absi, and G. Mariaux, "Finite element modeling of the different failure mechanisms of a plasma sprayed thermal barrier coatings system," Journal of Thermal Spray Technology, vol. 21, no. 6, pp. 1234-1244, 2012.

[19] Z. Lu, S. W. Myoung, Y. G. Jung, G. Balakrishnan, J. Lee, and U. Paik, "Thermal fatigue behavior of air-plasma sprayed thermal barrier coating with bond coat species in cyclic thermal exposure," Materials, vol. 6, no. 8, pp. 3387-3403, 2013. 

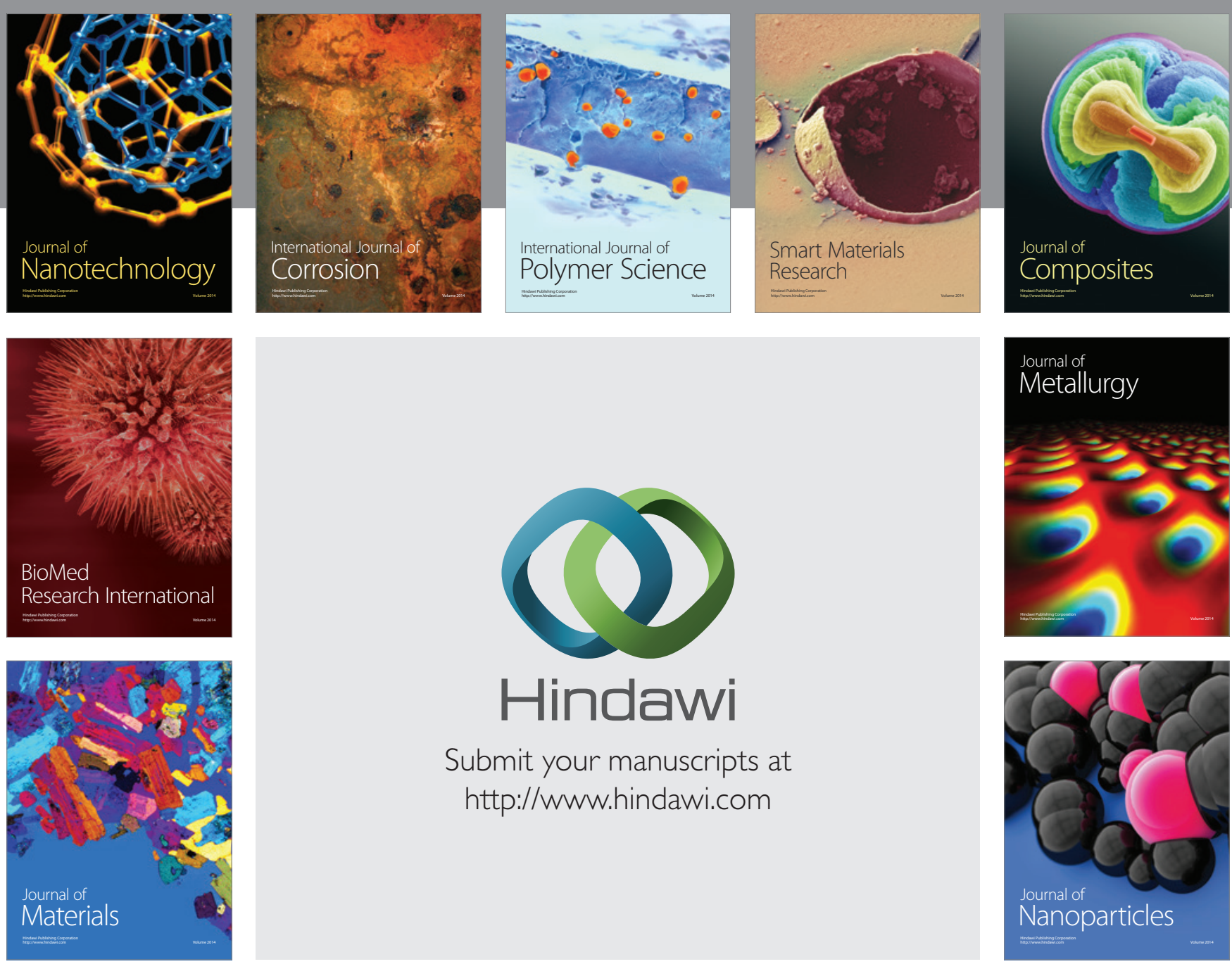

Submit your manuscripts at http://www.hindawi.com
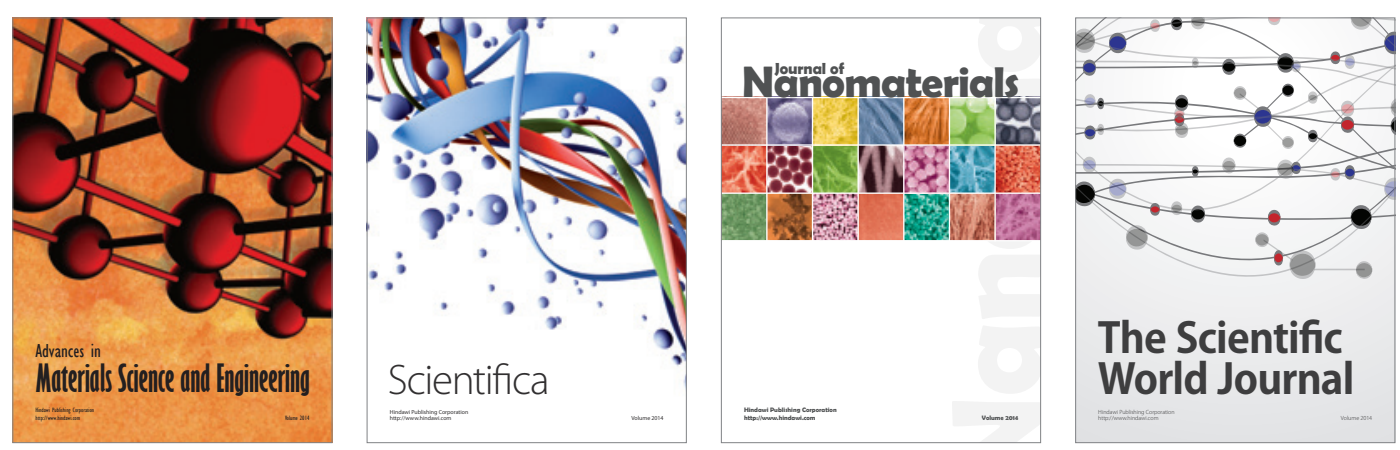

\section{The Scientific World Journal}
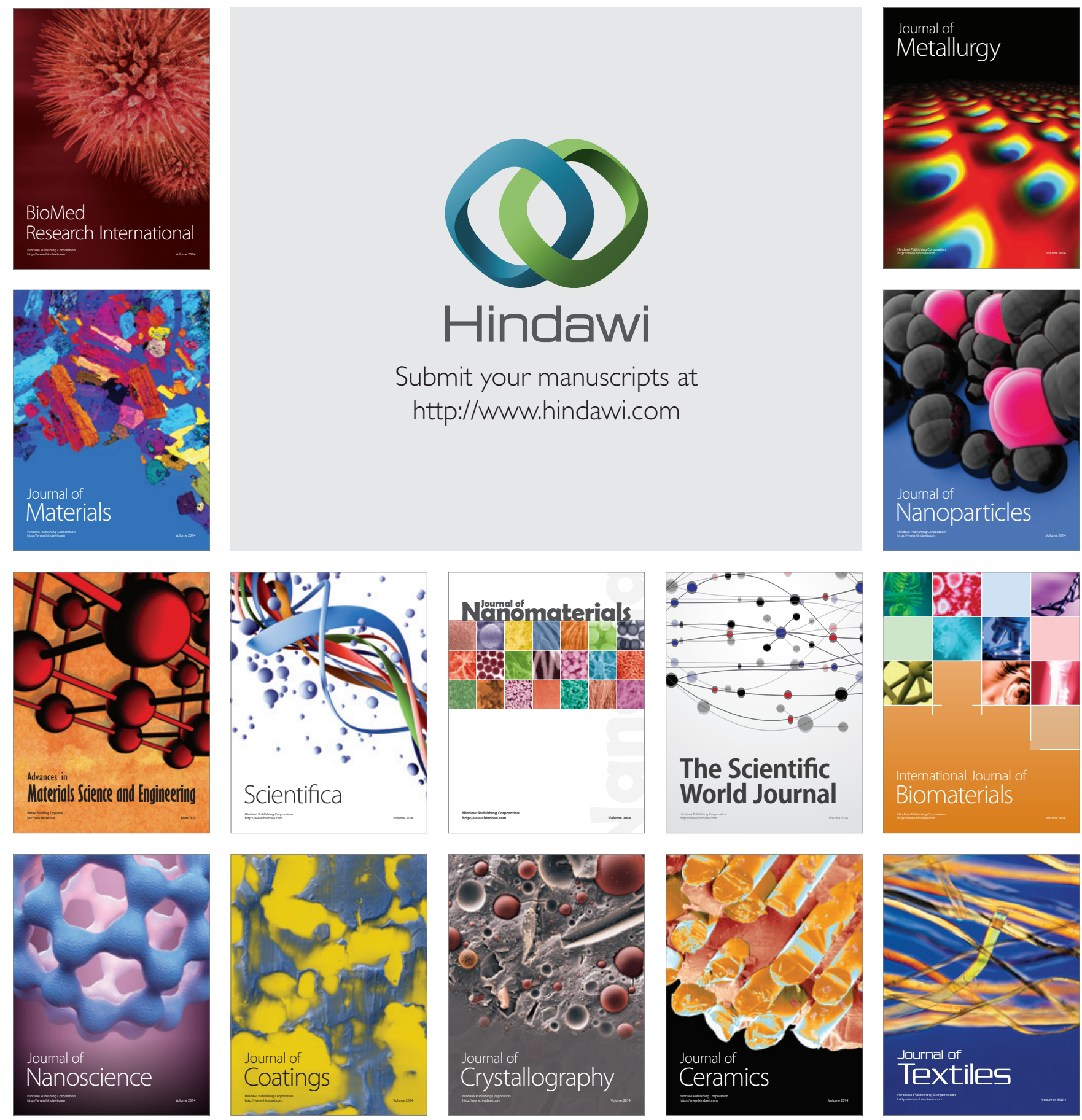